\title{
The Role of Propioni Bacterium acnes in Acne Vulgaris
}

\author{
Neama Ahmad Al-Nabati1, 2*, Ahmed Mahmoud Al-Hejin1, 3, Nouf Talal Mleeh", Noor Mohammed \\ Bataweel1, 3, Mohamed Abu-Zaid1, 5, Samah Omar Noor ${ }^{1,3}$, Maged Mostafa Mahmoud ${ }^{3,6}$, Azhar Abdullah \\ Najjar1, 3, Mohamed M. M. Ahmed1, 7 \\ ${ }^{1}$ Department of Biological Sciences, Faculty of Science, P.O. Box 80203, King Abdulaziz University, Jeddah, 21589, Saudi Arabia. \\ ${ }^{2}$ Department of Biological Sciences, Faculty of Science, P.O. Box 715, Um- Al-Qura University, Makkah, 21421, Saudi Arabia. \\ ${ }^{3}$ King Fahad Medical Research Center, P.O. Box 80216, King Abdulaziz University, Jeddah, 21589, Saudi Arabia. \\ ${ }^{4}$ Department of Dermatology, Faculty of Medicine, P.O. Box 80200, King Abdulaziz University, Jeddah, 21589, Saudi Arabia. \\ ${ }^{5}$ Microbial Genetics Department, Genetics Engineering and Biotechnology Division, National Research Center, Dokki, Giza, Egypt. \\ ${ }^{6}$ Molecular Genetics and Enzymology Department, Human Genetics and Genome Research, National Research Center, Cairo, Egypt. \\ ${ }^{7}$ Nucleic Acids Research Dept., Genetic Engineering, and Biotechnology Research Institute (GEBRI), City for Scientific Research and Technological \\ Applications. Alexandria, Egypt.
}

Correspondence Author: Neama Ahmad Al-Nabati, Department of Biological Sciences, Faculty of Science, P.0. Box 80203, King Abdulaziz University, Jeddah, 21589, Saudi Arabia.

${ }^{2}$ Department of Biological Sciences, Faculty of Science, P.O. Box 715, Um- Al-Qura University, Makkah, 21421, Saudi Arabia.

E-mail: nanabati@uqu.edu.sa

Received date: 12 February 2018, Accepted date: 12 April 2019, Online date: 20 April 2019

Copyright: (C) 2019 Neama Ahmad Al-Nabati et al., This is an open-access article distributed under the terms of the Creative Commons Attribution License, which permits unrestricted use, distribution, and reproduction in any medium, provided the original author and source are credited.

\begin{abstract}
Acne vulgaris is an inflammatory disease caused by opportunistic microorganism namely Propionibacterium acnes which thrive on the sebum and uses the nutrition's to develop the condition. P. acnes is Gram-positive, non-sporeforming, non-motile, rod-shaped bacterium, microaerophilic and anaerobic bacilli that grow best in anaerobic conditions under limited oxygen concentrations. This paper discusses the role and characteristics of $P$. acnes in the pathogenesis of acne disease. The mechanism involved in acnes include; abnormal production of sebum, abnormal keratinization, an inflammatory immune response, hormonal changes and a variety of mutation in genes such as polymorphisms in $I L-1 \alpha, T N F-\alpha$, and $C Y P 1 A 1$. Although the bacteria are part of normal microbiota, some studies linked $P$. acnes to other diseases some are corneal ulcers, endocarditis, sarcoidosis, cholesterol gallstones, hyperostosis, inflammation of lymph nodes, lungs, eyes, liver and osteitis (SAPHO) syndrome. The incidence of prevalence of antibiotic-resistant strains up to date is increasing, some of reasons is the characteristics of the bacteria such as biofilm formation, and phagocytosis. Studies to date investigated the role of $P$. acnes in acne vulgaris, until now, the relationship between acne and the bacterium is still in debate.
\end{abstract}

Key words: skin; microbiota; Propionibacterium acnes; acne vulgaris; antibiotics; MIC.

\section{INTRODUCTION}

Human skin is the largest organ of the human body and acts as the first line of defense. It contains microorganisms which form commensal microbial community or microbiota. The microbiota colonizes forming a complex barrier-like structure against the external environment. The most common microorganisms identified in the skin is of four main bacterial phyla; Actinobacteria, Firmicutes, Proteobacteria, and Bacteroidetes. The most three observed are Corynebacteria, Propionibacteria, and Staphylococci. Altering the combination of natural microbial communities or loss in the balance has been associated with chronic inflammatory skin diseases such as acne [1-2].

Acne vulgaris is an inflammatory disease caused by increased production of the sebum and appears as pimples [3]. The first early lesion in acne development is known as the micro-comedone can evolve into open, closed comedones, and inflammatory lesions such as papules, pustules, nodules, and cysts [4]. This paper discusses the role and characteristics of $P$. acnes in the pathogenesis of acne disease along with the emerging of antibiotic-resistant strains that requires attention.

\section{Acne an overview}

The skin consists of a hair follicle, sebaceous gland, and depend on balance in the sebum. The production of the sebum occurs by the sebaceous glands and causes the skin to moisten. Sebaceous sites are dominated by the bacterium 
Propionibacterium, whereas moist sites have Staphylococcus and Corynebacterium. In early adolescence hormones such as androgen plays a major role in the production of more sebum which blog pores along with dead cells and keeps skin moisturized. In the follicle, a bacterium that primarily thrives on the sebum such as Propionibacterium acnes uses the nutrition's to develop acne condition. This is the pre-stage to acne. The involvement of $P$. acnes in the pathogenesis of acne up to date is not fully understood [5-6].

Acne vulgaris is consistently represented the top three most prevalent skin conditions in the general population as found in large studies in the U.K., France, and the U.S.A which considered as one of the most common dermatological diseases that have an impact on young people worldwide. The etiology of acne vulgaris relatively depends on many factors such as genetics, environment, anxiety, and depression that impact the quality of life [7].

In western societies, acne vulgaris is widespread affecting approximately $79 \%$ to $95 \%$ of the adolescent population. Some studies show that acne is lower in non-industrial civilians than in western populations. In 1971, Schaefer [8] reported that acne was absent in Eskimo population before they moved to the modern life while Okinawa was an isolated island in south china sea during world war II and no signs of acne were there. On the other hand, In South Africa, dermatologists studied skin color in correlation to acne developments and found lower rates of acne among the Bantu population than whites [9-10-11].

A survey study made on the German population, researchers found that acne affects $64 \%$ of patients aged 20-29 years and 43\% of those between 30 and 39 years. Moreover, studies to date have focused on Caucasian and black skin types and fewer studies in Asian or Arab [12-13].

Yahya, 2009 [14] evaluated a cross-sectional study made in Africa of students with different age and stated that prevalence of acne increased with age (76.7\% at age $10-13$ years; $88.2 \%$ at age $14-16$ years; $97.1 \%$ at age $17-19$ years). The severity of acne made students feel low self-esteem and depression.

Another study made in south India, in older age groups, women were more likely to report having acne vulgaris than men while in China, Chinese undergraduates found that acne has a 78\% heritability in first-degree relatives [15-16].

\section{Characteristics of Propionibacterium acnes}

Propionibacterium acnes is Gram-positive non-spore-forming, non-motile, rod-shaped bacterium, microaerophilic and anaerobic bacilli. $P$. acnes grow best in anaerobic conditions under limited oxygen concentrations (0-20\%). Acne is not actually infectious disease since $P$. acnes is part of normal microbiota of healthy human skin; the normal flora of the oral cavity, large intestine, the conjunctiva, and the external ear canal [17-18]. The bacteria also normally reside in peripheral lung tissue and mediastinal lymph nodes [19].

$P$. acnes is slow growing and considered as a strict anaerobe, but it can tolerate oxygen up to $100 \%$ saturation. In vitro, $P$. acnes can survive for about 8 months without the need to subculture and under anaerobic conditions which allow the bacteria to survive in human tissues at low oxidation potentials. The ability of the bacterium to avoid phagocytosis is due to the organism's complex cell wall structure, which also has a surface fibrillar layer [17].

$P$. acnes has many phylotypes, the first namely type I (IA, IB) and II respectively. The differences between type I and II is in the sugar components of their cell walls and bacteriophage susceptibility. The identification between the two types can occur via serological agglutination tests, cell wall sugar analysis, bacteriophage susceptibility test, and immunofluorescence. Studies proved another distinct clade (subdivision) evolved into type III, adopted long filamentous cell structure that is not found with types I and II [4-20-21].

While $P$. acnes has always been linked to acnes, new findings show that $P$. acnes dominate the pilosebaceous follicles both in acne patients and in healthy skin with $89 \%$ to $94 \%$ respectively. However, some strains prone to be linked to acnes more such as type division IA were strongly associated with moderate to severe acne condition, while type IB, II and III, were associated with healthy skin [22].

Nakase et al [23] showed that subdivision type of phylotype IA1 was found almost in all severity acnes with $60 \%, 57.1 \%$ and $63.3 \%$ of strains found in the severe, moderate and mild acnes respectively, whereas phylotype IA2 was associated with severe and moderate acne. IA2 also emerged high resistance to antibiotic clindamycin.

Biofilm formation is another characteristic of $P$. acne, is a process by which bacteria irreversibly attach to each other growing on a surface which leads to a change in the phenotype and producing extracellular polymers facilitating adherence and matrix formation. $P$. acnes lead to the formation of an adhesive glue promoting the binding of corneocytes resulting in micro comedones [24].

Coenye et al [25]. showed that cells covered with $P$. acnes biofilm were more resistant to antimicrobial agents compared with planktonic cells.

The complete genome of $P$. acne has been sequenced and this bacterium has a single circular chromosome coding for 2333 genes, most of these genes encoding enzymes involved in degrading host tissues with five Christie-Atkins-Munch-Petersen (CAMP) factors acting as $2 \mathrm{~nm}$ membrane pore-forming toxins. The activation of these factors results in the initiation of inflammation. Other genes which are involved in metabolic reconstruction such as changing oxygen making $P$. acnes grow under aerobic and anaerobic environment. The rest of the genes encodes degradative enzymes that may use host-derived substances [24$26]$.

\section{Role of $P$. acne in the pathogenesis of the disease}


The mechanisms involved in the pathogenesis of $P$. acnes have been proposed [27-28]. First, bacterial enzymes such as lipases, degrade and damage the host tissues and cells. Second, immunogenic factors of $P$. acnes such as heat shock proteins (HSPs) may trigger inflammation [29-30].

The most three main factors which play important role in the pathogenesis of acne: (i) The stimulation of the sebaceous gland lead to increasing in the production of the sebum which occurs due to activated receptors including those for androgens, neuropeptides, insulin-like growth factor-I and peroxisome proliferator-activated receptors (PPAR), the expression of tumor necrosis factor (TNF), toll-like receptors (TLRs), (ii) abnormal keratinization of the sebaceous duct and comedone formation, (iii) an inflammatory immune response in which $P$. acnes and the innate immunity play an important role. There are many other factors contribute to acne these include; irritation, cosmetics, and diet [1-4-31].

The severity of acne is also correlated with an increased level of stress, hormone, and genetics. Some studies showed that hormonal changes during puberty contributed to acne vulgaris. The hormones linked to acne; androgen, testosterone, dehydroepiandrosterone, and dihydrotestosterone, as well as insulin-like growth factor 1 . On the other hand, genetic studies linked a variety of genes such as polymorphisms in $I L-1 \alpha, T N F-\alpha$, and $C Y P 1 A 1$ among first degree relatives, as well as twin studies [3233-34].

\section{P. acnes associated with other diseases}

Although $P$. acnes is generally considered harmless, there's proof that the bacterium has been considered a low virulence, yet it has been associated with many diseases these include, corneal ulcers; endocarditis; sarcoidosis; cholesterol gallstones; allergic alveolitis; pulmonary angiitis; and synovitis, acne, pustulosis, hyperostosis, and osteitis (SAPHO) syndrome [35-36].

Ishige et al [37] proved that P. acne DNA was detected in lymph nodes of Japanese individuals with sarcoidosis which is a granulomatous disease that results in the inflammation of lymph nodes, lungs, eyes, liver, and other tissues, while Stirling et al [38] showed that $P$. acnes was isolated from intervertebral disc material of patients who suffered from severe sciatica and they hypothesize that $P$. acnes is considered low virulent organisms and can gain access to the injured spinal disc and begin chronic inflammation.

\section{Resistance to antibiotic}

Scientists have the long question whether $P$. acne is resistant to antibiotics according to some studies [39-40-41-42-43-44-4546-47-48-49-50-51].

The incidence of resistance has increased from $20 \%$ in 1978 to $62 \%$ in 1996 . Strains of $P$. acnes developed resistance mostly to erythromycin, clindamycin, tetracycline, doxycycline, and trimethoprim. A study revealed that five out of twenty-two patients had resistance to high levels of clindamycin, whereas four of twenty-one patients high with erythromycin and demonstrated that strains of $P$. acnes with an extremely high minimum inhibitory concentration (MIC) to erythromycin, tetracycline, and clindamycin has emerged [52-53].

In addition, another study evaluated the minimum inhibitory concentration (MIC) of $P$. acnes in seventy-five acne patients receiving long-term antibiotic therapy revealed the emergence of resistant strains. The mean of MIC value of tetracycline tested on thirty-three patients receiving long-term was four to five times higher than that in control free-acne groups not receiving antibiotic therapy. The study shows that patients with high acnes correlated to antibiotic-resistant strains [54]. Some of the reasons recorded with mutations in $16 \mathrm{~S}$ and $23 \mathrm{~S}$ identified in the UK and reported high-level resistance to minocycline, tetracycline and other unidentified mutations [55-56-57].

A recent study by sardana et al [58] showed the emerging of high antibiotic resistance strains that were isolated from patients receiving antibiotics. The antibiotics recorded were; azithromycin (100\%) erythromycin (98\%), clindamycin (90.4\%). In contrast, minocycline was low resistance.

\section{CONCLUSION}

Propionibacterium acnes is known as the main causative agent of acne and can form other infections such as inflammation of lymph nodes, lungs, eyes, liver, corneal ulcers; endocarditis; sarcoidosis; cholesterol gallstones; allergic alveolitis; pulmonary angiitis; and other tissues. Studies to date investigated the role of $P$. acnes in acne vulgaris, until now, the relationship between acne and the bacterium is still in the debate ${ }^{[2]}$.

The emerging of antibiotic-resistant strains is becoming a challenge. New methods in regard to acne should aim to reduce the bacterium ability to initiate inflammation and retain the natural skin barrier with agents or treatments which do not cause bacterial resistance and to further regulate the production of sebum.

\section{CONFLICT OF INTEREST}

The authors declare no conflicts of interest. 
The authors also, acknowledge assistance from the Dept. of Biological Sciences, Faculty of Science, King Abdulaziz University (KAU), Jeddah, KSA.

\section{REFERENCES}

1. Dréno, B. 2017. What is new in the pathophysiology of acne, an overview. Journal of the European Academy of Dermatology and Venereology 31: 8-12.

2. Byrd, A. L., Belkaid, Y., \& Segre, J. A. 2018. the human skin microbiome. Nature Reviews Microbiology $16(3): 143$.

3. Williams, H. C., Dellavalle, R. P., \& Garner, S. 2012. Acne vulgaris. The Lancet 379(9813): 361-372.

4. Omer, H., McDowell, A., \& Alexeyev, O. A. 2017. Understanding the role of Propionibacterium acnes in acne vulgaris: The critical importance of skin sampling methodologies. Clinics in Dermatology 35(2): 118-129.

5. Nasri, H., Bahmani, M., Shahinfard, N., Nafchi, A.M., Saberianpour, S. and Kopaei, M.R. 2015. Medicinal plants for the treatment of acne vulgaris: a review of recent evidences. Jundishapur journal of microbiology 8(11).

6. O’Neill, A. M., \& Gallo, R. L. 2018. Host-microbiome interactions and recent progress into understanding the biology of acne vulgaris. Microbiome 6(1): 177.

7. Bhate, K. and Williams, H.C. 2013. Epidemiology of acne vulgaris. British Journal of Dermatology 168(3): 474-485.

8. Schaefer, O. 1971. When the Eskimo comes to town. Nutrition Today 6(6): 8-16.

9. FINDLAY, O. 1967. The age incidence of common skin diseases in the white population of the Transvaal. British Journal of Dermatology 79(10): 538-538.

10. Park, R.G. 1968. The age distribution of common skin disorders in the Bantu of Pretoria, Transvaal. British Journal of Dermatology 80(11): 758-759.

11. Cordain, L., Lindeberg, S., Hurtado, M., Hill, K., Eaton, S.B. and Brand-Miller, J. 2002. Acne vulgaris: a disease of Western civilization. Archives of dermatology 138(12): 1584-1590.

12. Schäfer, T., Nienhaus, A., Vieluf, D., Berger, J. and Ring, J. 2001. Epidemiology of acne in the general population: the risk of smoking. British journal of dermatology 145(1): 100-104.

13. Taylor, S.C., Cook-Bolden, F., Rahman, Z. and Strachan, D. 2002. Acne vulgaris in skin of color. Journal of the American Academy of Dermatology 46(2): S98-S106.

14. Yahya, H. 2009. Acne vulgaris in Nigerian adolescents-prevalence, severity, beliefs, perceptions, and practices. International journal of dermatology 48(5): 498-505.

15. Adityan, B. and Thappa, D.M. 2009. Profile of acne vulgaris-A hospital-based study from South India. Indian Journal of Dermatology, Venereology, and Leprology 75(3): 272.

16. Wei, B., Pang, Y., Zhu, H., Qu, L., Xiao, T., Wei, H.C., Chen, H.D. and He, C.D. 2010. The epidemiology of adolescent acne in North East China. Journal of the European Academy of Dermatology and Venereology 24(8): 953-957.

17. Perry, A.L. and Lambert, P.A. 2006. Propionibacterium acnes. Letters in applied microbiology 42(3): $185-188$.

18. Capoor, M. N., Ruzicka, F., Machackova, T., Jancalek, R., Smrcka, M., Schmitz, J. E., \&Ahmed, F.S. 2016. Prevalence of propionibacterium acnes in intervertebral discs of patients undergoing lumbar microdiscectomy: a prospective cross-sectional study. PLoS One 11(8): e0161676.

19. Ishige, I., Eishi, Y., Takemura, T., Kobayashi, I., Nakata, K., Tanaka, I., Nagaoka, S., Iwai, K. et al. 2005. Propionibacterium acnes is the most common bacterium commensal in peripheral lung tissue and mediastinal lymph nodes from subjects without sarcoidosis. Sarcoidosis Vasc Diffuse Lung Dis 22(1): 33-42.

20. Lomholt, H. B., \& Kilian, M. 2010. Population genetic analysis of Propionibacterium acnes identifies a subpopulation and epidemic clones associated with acne. PLoS One 5(8): e12277.

21. Kwon, H. H., \& Suh, D. H. 2016. Recent progress in the research about Propionibacterium acnes strain diversity and acne: pathogen or bystander?. International Journal of Dermatology 55(11): 1196-1204.

22. Dréno, B., Pécastaings, S., Corvec, S., Veraldi, S., Khammari, A., \& Roques, C. 2018. Cutibacterium acnes (Propionibacterium acnes) and acne vulgaris: a brief look at the latest updates. Journal of the European Academy of Dermatology and Venereology 32: 5-14.

23. Nakase, K., Hayashi, N., Akiyama, Y., Aoki, S., \& Noguchi, N. 2017. Antimicrobial susceptibility and phylogenetic analysis of Propionibacterium acnes isolated from acne patients in Japan between 2013 and 2015. The Journal of dermatology 44(11): 1248-1254.

24. Beylot, C., Auffret, N., Poli, F., Claudel, J.P., Leccia, M.T., Del Giudice, P. and Dreno, B. 2014. Propionibacterium acnes: an update on its role in the pathogenesis of acne. Journal of the European Academy of Dermatology and Venereology 28(3): 271-278.

25. Coenye, T., Peeters, E. and Nelis, H.J. 2007. Biofilm formation by Propionibacterium acnes is associated with increased resistance to antimicrobial agents and increased production of putative virulence factors. Research in microbiology 158(4): 386-392.

26. Brüggemann, H., Henne, A., Hoster, F., Liesegang, H., Wiezer, A., Strittmatter, A., Hujer, S., Dürre, P. and Gottschalk, G. 2004. The complete genome sequence of Propionibacterium acnes, a commensal of human skin. Science 305(5684): 671-673.

27. Holland, K.T., Aldana, O., Bojar, R.A., Cunliffe, W.J., Eady, E.A., Holland, D.B., Ingham, E., McGeown, C., Till, A. and Walters, C. 1998. Propionibacterium acnes and acne. Dermatology 196(1): 67-68. 
28. Jappe, U., Ingham, E., Henwood, J. and Holland, K.T. 2002. Propionibacterium acnes and inflammation in acne; P. acnes has T-cell mitogenic activity. British Journal of Dermatology 146(2): 202-209.

29. Farrar, M.D., Ingham, E. and Holland, K.T. 2000. Heat shock proteins and inflammatory acne vulgaris: molecular cloning, overexpression and purification of a Propionibacterium acnes GroEL and DnaK homologue. FEMS microbiology letters 191(2): 183-186.

30. Koreck, A., Pivarcsi, A., Dobozy, A. and Kemeny, L. 2003. The role of innate immunity in the pathogenesis of acne. Dermatology 206(2): 96-105.

31. Achermann, Y., Goldstein, E. J., Coenye, T., \& Shirtliff, M. E. 2014. Propionibacterium acnes: from commensal to opportunistic biofilm-associated implant pathogen. Clinical microbiology reviews 27(3): 419-440.

32. Taylor, M., Gonzalez, M., \& Porter, R. 2011. Pathways to inflammation: acne pathophysiology. European Journal of Dermatology 21(3): 323-333.

33. Chiu, A., Chon, S. Y., \& Kimball, A. B. 2003. The response of skin disease to stress: changes in the severity of acne vulgaris as affected by examination stress. Archives of dermatology 139(7): 897-900.

34. Melnik, B., Jansen, T., \& Grabbe, S. 2007. Abuse of anabolic-androgenic steroids and bodybuilding acne: an underestimated health problem. JDDG: Journal der Deutschen Dermatologischen Gesellschaft 5(2): 110-117.

35. Jakab, E., Zbinden, R., Gubler, J., Ruef, C., Von Graevenitz, A. and Krause, M. 1996. Severe infections caused by propionibacterium acnes: an underestimated pathogen in late postoperative infections. The Yale journal of biology and medicine 69(6): 477.

36. Yamada, T., Eishi, Y., Ikeda, S., Ishige, I., Suzuki, T., Takemura, T., Takizawa, T. and Koike, M. 2002. In situ localization of Propionibacterium acnes DNA in lymph nodes from sarcoidosis patients by signal amplification with catalysed reporter deposition. The Journal of pathology 198(4): 541-547.

37. Ishige I, Usui Y, Takemura T, Eishi Y. 1999. Quantitative PCR of mycobacterial and propionibacterial DNA in lymph nodes of Japanese patients with sarcoidosis. Lancet 354: 120-123.

38. Stirling, A., Worthington, T., Rafiq, M., Lambert, P. A., \& Elliott, T. S. 2001. Association between sciatica and Propionibacterium acnes. The Lancet 357(9273): 2024-2025.

39. Coates, P., Vyakrnam, S., Eady, E. A., Jones, C. E., Cove, J. H., \& Cunliffe, W. J. 2002. Prevalence of antibiotic-resistant propionibacteria on the skin of acne patients: 10-year surveillance data and snapshot distribution study. British Journal of Dermatology 146(5): 840-848.

40. Ross, J. I., Snelling, A. M., Carnegie, E., Coates, P., Cunliffe, W. J., Bettoli, V., \& Török, L. 2003. Antibiotic-resistant acne: lessons from Europe. British journal of Dermatology 148(3): 467-478.

41. Oprica, C., Nord, C. E., \& ESCMID Study Group on Antimicrobial Resistance in Anaerobic Bacteria. 2005. European surveillance study on the antibiotic susceptibility of Propionibacterium acnes. Clinical microbiology and infection 11(3): 204213.

42. Bettoli, V., Borghi, A., Rossi, R., Ferroni, M., Rigolin, F., \& Virgili, A. 2006. Antibiotic resistance of propionibacteria. Dermatology 212(2): 206-207.

43. Dumont-Wallon, G., Moyse, D., Blouin, E., \& Dréno, B. 2010. Bacterial resistance in French acne patients. International journal of dermatology 49(3): 283-288.

44. Vares, B., Zandi, S., \& Abdollahi, H. 2011. Determination of microbial agents of acne vulgaris and Propionibacterium acnes antibiotic resistance in patients referred to dermatology clinics in Kerman, Iran. Jundishapur Journal of Microbiology 4(1): $17-22$.

45. Moon, S. H., Roh, H. S., Kim, Y. H., Kim, J. E., Ko, J. Y., \& Ro, Y. S. 2012. Antibiotic resistance of microbial strains isolated from Korean acne patients. The Journal of dermatology 39(10): 833-837.

46. Luk, N. M., Hui, M., Lee, H. C., Fu, L. H., Liu, Z. H., Lam, L. Y., \& Siu, F. Y. 2013. Antibiotic-resistant Propionibacterium acnes among acne patients in a regional skin centre in Hong Kong. Journal of the European Academy of Dermatology and Venereology 27(1): 31-36.

47. Abdel Fattah, N. S. A., \& Darwish, Y. W. 2013. In vitro antibiotic susceptibility patterns of Propionibacterium acnes isolated from acne patients: an Egyptian university hospital-based study. Journal of the European Academy of Dermatology and Venereology 27(12): 1546-1551.

48. Nakase, K., Nakaminami, H., Takenaka, Y., Hayashi, N., Kawashima, M., \& Noguchi, N. 2014. Relationship between the severity of acne vulgaris and antimicrobial resistance of bacteria isolated from acne lesions in a hospital in Japan. Journal of medical microbiology 63(5): 721-728.

49. Giannopoulos, L., Papaparaskevas, J., Refene, E., Daikos, G., Stavrianeas, N., \& Tsakris, A. 2015. MLST typing of antimicrobial-resistant Propionibacterium acnes isolates from patients with moderate to severe acne vulgaris. Anaerobe 31 : $50-54$.

50. Sardana, K., Gupta, T., Garg, V. K., \& Ghunawat, S. 2015. Antibiotic resistance to Propionobacterium acnes: worldwide scenario, diagnosis and management. Expert review of anti-infective therapy 13(7): 883-896.

51. Doğan, B., Bektöre, B., Karabacak, E., \& Özyurt, M. 2017. Resistance status of antibiotics in Gram-positive bacteria isolated from acne lesions in İstanbul. TURKDERM-Archieves of The Turkish Dermatology and Venerology 51(2): 32-36.

52. Guin, J. D., Huber, D. S., \& Gielerak, P. L. 1979. Antibiotic sensitivity of comedonal Propionibacterium acnes. Acta dermato-venereologica 59(6): 552-554. 
53. Cooper, A. J. 1998. Systematic review of Propionibacterium acnes resistance to systemic antibiotics. The Medical Journal of Australia 169(5): 259-261.

54. Leyden, J. J., McGinley, K. J., Cavalieri, S., Webster, G. F., Mills, O. H., \& Kligman, A. M. 1983. Propionibacterium acnes resistance to antibiotics in acne patients. Journal of the American Academy of Dermatology 8(1): 41-45.

55. Ross, J. I., Snelling, A. M., Eady, E. A., Cove, J. H., Cunliffe, W. J., Leyden, J. J., \& Oshima, S. 2001. Phenotypic and genotypic characterization of antibiotic-resistant Propionibacterium acnes isolated from acne patients attending dermatology clinics in Europe, the USA, Japan and Australia. British Journal of Dermatology 144(2): 339-346.

56. Aubin, G. G., Portillo, M. E., Trampuz, A., \& Corvec, S. 2014. Propionibacterium acnes, an emerging pathogen: from acne to implant-infections, from phylotype to resistance. Medecine et maladies infectieuses 44(6): 241-250.

57. Dessinioti, C., \& Katsambas, A. 2017. Propionibacterium acnes and antimicrobial resistance in acne. Clinics in dermatology 35(2): 163-167.

58. Sardana, K., Gupta, T., Kumar, B., Gautam, H. K., \& Garg, V. K. 2016. Cross-sectional pilot study of antibiotic resistance in Propionibacterium Acnes strains in Indian acne patients using 16S-RNA polymerase chain reaction: a comparison among treatment modalities including antibiotics, benzoyl peroxide, and isotretinoin. Indian journal of dermatology 61(1): 45 . 